\title{
Antimicrobial activity of doripenem against bacterial isolates from humans and animals
}

The Journal of Antibiotics (2010) 63, 631-632; doi:10.1038/ja.2010.97; published online 18 August 2010

$\beta$-Lactam antibiotics, such as penicillins, cephalosporins and carbapenems, are the largest family of antimicrobial agents, and have been widely used in this clinical practice. ${ }^{1}$ However, the emergence and the increased frequency of antimicrobial resistance has become a serious health problem. For this reason, the development of new antimicrobial drugs becomes a worldwide priority. Doripenem (formerly known as S-4661) is a new synthetic $1-\beta$-methyl carbapenem antibiotic developed by Shionogi (Osaka, Japan). Doripenem is a new synthetic $1-\beta$-methyl carbapenem antibiotic with a broad-spectrum activity against clinically pathogens including Enterobacteriaceae, nonfermenting gram-negative, anaerobes, and many gram-positive both in vivo and in vitro, including some carbapenem resistant. ${ }^{2-5}$ Recently, doripenem was indicated in the United States and Europe for the treatment of intraabdominal and complicated urinary tract infections including pyelonephritis, and approved in the Europe for patients with nosocomial pneumonia including ventilator-associated pneumonia. ${ }^{4}$

The aim of this study is to evaluate the in vitro activity of doripenem against enterococci and E. coli isolates from wild animals, pigs, pets, poultry and humans in Portugal.
A total of 938 isolates were tested, including 522 enterococci and 416 E. coli (62 of which produced extended-spectrum $\beta$-lactamases (ESBLs)) were previously recovered from fecal samples of human and animal origin and characterized by using specific primers to species identification and detection of antibiotic resistant genes. ${ }^{6}$ Doripenem standard powder was provided by Johnson \& Johnson Pharmaceutical Research \& Development, LLC (Raritan, NJ, USA). Doripenem dilutions were prepared and dissolved as recommended by the manufacturer, from a stock solution. The minimum inhibitory concentration (MIC) of doriopenen were

Table 1 In vitro activity of doripenem against Escherichia faecium, E. faecalis, E. coli and ESBL-containing E. coli isolates from human and animal origin

\begin{tabular}{|c|c|c|c|c|c|c|c|c|c|c|c|c|c|c|c|c|c|c|}
\hline \multirow[b]{2}{*}{ Species } & \multirow[b]{2}{*}{ Source } & \multirow{2}{*}{$\begin{array}{c}\text { Number of } \\
\text { isolates }\end{array}$} & \multicolumn{14}{|c|}{ Number of isolates at each doripenem MIC $\left(\mathrm{mgl}^{-1}\right)$} & \multirow[b]{2}{*}{$M I C_{50}$} & \multirow[b]{2}{*}{$M I C_{90}$} \\
\hline & & & 0.031 & 0.062 & 0.125 & 0.25 & 0.5 & 1 & 2 & 4 & 8 & 16 & 32 & 64 & 128 & $>128$ & & \\
\hline \multirow[t]{4}{*}{ E. faecalis } & Human & 40 & & & & & & 5 & 6 & 10 & 17 & 2 & & & & & 4 & 8 \\
\hline & Poultry & 92 & & & & & & & 6 & 51 & 31 & 4 & & & & & 4 & 8 \\
\hline & Pets & 45 & & & & & & 7 & 11 & 9 & 15 & 3 & & & & & 4 & 8 \\
\hline & Wild animals & 73 & & & & & 11 & 13 & 25 & 17 & 7 & & & & & & 2 & 4 \\
\hline \multirow[t]{4}{*}{ E. faecium } & Human & 106 & & & & & & & & & & 7 & 10 & 7 & 32 & 50 & 128 & $>128$ \\
\hline & Poultry & 54 & & & & & & & & & & & 4 & 7 & 19 & 24 & 128 & $>128$ \\
\hline & Pets & 67 & & & & & & & & & & 1 & 4 & 33 & 29 & & 64 & 128 \\
\hline & Wild animals & 45 & & & & & & & & & & 2 & 12 & 13 & 14 & 4 & 64 & 128 \\
\hline \multirow[t]{4}{*}{ E. coli } & Human & 92 & 42 & 18 & 12 & 20 & & & & & & & & & & & 0.062 & 0.25 \\
\hline & Swine & 64 & 35 & 8 & 21 & & & & & & & & & & & & 0.031 & 0.125 \\
\hline & Poultry & 72 & 40 & 14 & 16 & 2 & & & & & & & & & & & 0.031 & 0.125 \\
\hline & Wild animals & 126 & 118 & 6 & 2 & & & & & & & & & & & & 0.031 & 0.031 \\
\hline \multirow[t]{4}{*}{ ESBL-containing $E$. coli } & Human & 3 & 3 & & & & & & & & & & & & & & $N A^{a}$ & $N A^{a}$ \\
\hline & Swine & 16 & 15 & 1 & & & & & & & & & & & & & 0.031 & 0.031 \\
\hline & Poultry & 24 & 14 & 3 & 7 & & & & & & & & & & & & 0.031 & 0.125 \\
\hline & Wild animals & 19 & 18 & 1 & & & & & & & & & & & & & 0.031 & 0.031 \\
\hline
\end{tabular}

Abbreviations: ESBL, extended-spectrum $\beta$-lactamases; MIC, minimum inhibitory concentration.

${ }^{a} \mathrm{NA}$, not applicable. Insufficient strains to calculate $\mathrm{MIC}_{50}$ and $\mathrm{MIC}_{90}$. 
determined using the Clinical Laboratory Standards Institute microbroth dilution method. ${ }^{7}$ The reference strains tested included E. faecalis ATCC 29212 and E. coli ATCC 25922. Interpretation of MIC results was performed in accordance with Clinical Laboratory Standards Institute breakpoints criteria.

The distribution of the doripenem MICs against enterococci and E. coli isolates, from different species and origins, is shown in Table 1. All the E. faecalis were inhibited by $\leqslant 16.0 \mathrm{mg} \mathrm{l}^{-1}$ doripenem, whereas E. faecium isolates showed higher doripenem MIC values (range from 16.0 to $\geqslant 128 \mathrm{mgl}^{-1}$ ). These results are very similar to those obtained during the surveillance study reports against gram-positive pathogens, wherein the $\mathrm{MIC}_{50}$ and $\mathrm{MIC}_{90}$ values were 4 and $8 \mathrm{mgl}^{-1}$, respectively. Although doripenem inhibited $E$. faecalis isolates the clinical significance of this surveillance data remains uncertain. ${ }^{3}$ Moreover, the enterococci isolates from wild animals showed twofold more susceptibility to doripenem in comparison with other enterococcal origin, except in the E. faecium pets isolates, in which it showed an identical $\mathrm{MIC}_{50}$ and $\mathrm{MIC}_{90}$.

The E. coli isolates were significantly more susceptible than enterococci isolates, with $\mathrm{MIC}_{50}$ and $\mathrm{MIC}_{90}$ values between 0.031 and $0.25 \mathrm{mgl}^{-1}$, respectively. The doripenem activity against $E$. coli was similar to that demonstrated recently by others for doripenem activity against Enterobacteriaceae, in which the overall $\mathrm{MIC}_{90}$ values have ranged from 0.03 to $0.5 \mathrm{mgl}^{-1}$. It is interesting to underline the relatively lower susceptibility of the human E. coli isolates to the doripenem, showing a $\mathrm{MIC}_{50}$ and $\mathrm{MIC}_{90}$ twofold greater than animal E. coli isolates. This lower susceptibility in human isolates can reflect the different use of antimicrobials in humans, animals, and consequently in the environment. In general, ESBL producers show lower susceptibility to the majority of the beta-lactam antibiotics than the non-producers. ${ }^{5}$ Our study showed that ESBL-containing E. coli isolates are susceptible to doripenem with $\mathrm{MIC}_{50}$ and $\mathrm{MIC}_{90}$ values between 0.031 and $0.125 \mathrm{mg} \mathrm{l}^{-1}$, respectively. These present data support the findings of others authors, wherein doripenem, as others carbapenems, meropenem and imipenem, remains active against ESBL-containing Enterobacteriaceae. ${ }^{5,8}$

In summary, although doripenem has not been effective among enterococci, our in vitro study has shown that this new antibiotic is a potent agent against E. coli, including ESBLcontaining $E$. coli isolates, and can be an attractive choice, alone or in combination with others antimicrobial agents, to optimize therapeutic treatment success, including infections caused by multidrug resistant strains.

\section{ACKNOWLEDGEMENTS}

We thank Johnson \& Johnson Pharmaceutical Research \& Development, LLC for their contribution to supply the powder compound doripenem.

Gilberto Igrejas ${ }^{1,2}$, Nuno Silva
Hajer Radhouani $1^{1,2,3,4}$,
Alexandre Gonçalves ${ }^{1,2,3,4}$,
Carlos Araújo $^{1,2,3,4}$, Jorge Rodrigues
Patrícia Poeta $^{3,4}$ and

${ }^{1}$ Department of Genetics and Biotechnology, University of Trás-osMontes and Alto Douro, Vila Real, Portugal; ${ }^{2}$ Institute for Biotechnology and Bioengineering, Centre of Genomics and Biotechnology, University of Trás-osMontes and Alto Douro, Vila Real, Portugal; ${ }^{3}$ Department of Veterinary Sciences, University of Trás-os-Montes and Alto Douro, Vila Real, Portugal and

${ }^{4}$ Veterinary and Animal Science Research Centre (CECAV), Vila Real, Portugal E-mail: ppoeta@utad.pt

1 Suarez, C. \& Gudiol, F. [Beta-lactam antibiotics]. Enferm. Infecc. Microbiol. Clin. 27, 116-129 (2009).

2 Anderson, D. L. Doripenem. Drugs Today (Barc) 42, 399-404 (2006).

3 Fritsche, T. R., Sader, H. S., Stillwell, M. G. \& Jones, R. N. Antimicrobial activity of doripenem tested against prevalent Gram-positive pathogens: results from a global surveillance study (2003-2007). Diagn. Microbiol. Infect. Dis. 63, 440-446 (2009).

4 Keam, S. J. Doripenem: a review of its use in the treatment of bacterial infections. Drugs. 68, 2021-2057 (2008).

5 Mendes, R. E., Rhomberg, P. R., Bell, J. M., Turnidge, J. D. \& Sader, H. S. Doripenem activity tested against a global collection of Enterobacteriaceae, including isolates resistant to other extended-spectrum agents. Diagn. Microbiol. Infect. Dis. 63, 415-425 (2009).

6 Poeta, P., Costa, D., Rodrigues, J. \& Torres, C. Antimicrobial resistance and the mechanisms implicated in faecal enterococci from healthy humans, poultry and pets in Portugal. Int. J. Antimicrob. Agents. 27, 131-137 (2006).

7 Clinical and Laboratory Standards Institute. Performance Standards for Antimicrobial Susceptibility Testing: Seventeenth Informational Supplement. CLSI document M100-S17, (Wayne, PA, 2007).

8 Mushtaq, S., Ge, Y. \& Livermore, D. M. Comparative activities of doripenem versus isolates, mutants, and transconjugants of Enterobacteriaceae and Acinetobacter spp. with characterized beta-lactamases. Antimicrob. Agents Chemother. 48, 1313-1319 (2004). 